NASA Technical Memorandum 106033

$$
1 N-39
$$

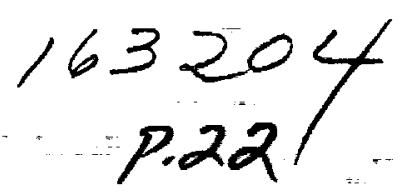

\title{
Structural Tailoring of Aircraft Engine Blade Subject to Ice Impact Constraints
}

E.S. Reddy and G.H. Abumeri

Sverdrup Technology, Inc.

Lewis Research Center Group

Brook Park, Ohio

and

-P.L.N. Murthy and C.C. Chamis

National Aeronautics and Space Administration

Lewis Research Center

Cleveland, Ohio

Prepared for the

Fourth AIAA/Air Force/NASA/OAI Symposium on Multidisciplinary Analysis cosponsored by the AIAA, USAF, NASA, and OAI

Cleveland, Ohio, September 21-23, 1992

(NASA-TM-106033) STRUCTURAL

TAILORING OF AIRCRAFT ENGINE BLADE SUBJECT TO ICE IMPACT CONSTRAINTS (NASA) $22 \mathrm{p}$
N93-26999

Unclas 


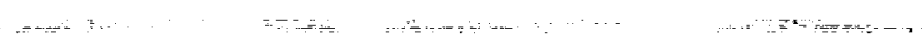

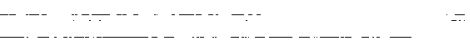

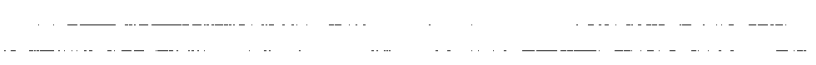




\title{
STRUCTURAL TAILORING OF AIRCRAFT ENGINE BLADE SUBJECT TO ICE IMPACT CONSTRAINTS
}

\author{
E. S. Reddy and G. H. Abumeri \\ Sverdrup Technology, Inc. \\ Lewis Research Center Group \\ Brook Park, Ohio \\ P. L. N. Murthy and C. C. Chamis \\ NASA Lewis Research Center \\ Cleveland, Ohio
}

\begin{abstract}
Results are presented for the minimum weight design of SR2 unswept blade made of [Titanium/ Graphite-Epoxy/Titanium]s fiber composite. The blade which is rotating at high RPM is subject to ice impact. The root chord length, blade thicknesses at five stations, and graphite-epoxy ply orientation are chosen as design variables. Design constraints are placed on the behavior variables: local leading edge strain and root damage parameter (combined stress failure criteria) as a function due to ice impact, maximum spanwise centrifugal stress at the root of the deformed blade due to local damage, first three natural frequencies and resonance margin after impact. The method of feasible directions is employed to solve the inequality constrained minimization problem. The effect of ice speed and the ice impact location on the final design are discussed.
\end{abstract}

\section{INTRODUCTION}

When aircrafts fly through clouds of super-cooled water droplets, ice formation occurs on forward facing structural components. One such component is the engine inlet. With time, the ice accretes on the inlet and eventually sheds due to structural vibrations as shown in Figure 1. As a result, blocks of ice travelling at high speeds impacts the engine blades that are rotating at high RPM. This process may cause severe damage to the blade and subsequently to the engine. Therefore, it is necessary to properly account for ice impact during the blade design. 
Fibrous composites are ideal for structural applications such as high performance aircraft engine blades where high strength-to-weight and stiffness-to-weight ratios are required. These factors along with the flexibility to select the composite layup and to favorably orient fiber directions help limit both the impact damage and stresses arising from large rotational speeds.

The most effective way to consider impact damage damage and rotational stresses simultaneously for a specific design is through formal optimization. The objective of this paper is to describe the use of the NASA in-house code $B L A S I M^{1}$ to perform structural tailoring of blades subject to ice impact . The SR2 2 unswept blade made of [Titanium/Graphite-Epoxy/Titanium] $]_{S}$ fiber composite is considered for numerical study. The ice piece is modeled as an equivalent spherical object impacting on the leading edge of the blade. The direction of ice piece is opposite to that of the aircraft.

The root chord length, thicknesses at five stations along the span of the blade, composite layer thicknesses and fiber orientation of graphite-epoxy ply are considered as design variables. Constraints are placed on average leading edge strain due to local damage, root damage caused by the impact, maximum centrifugal stress at the root of the dented blade due to local plastic deformations, first three natural frequencies and one resonance margin (mode-I and 2nd engine order intersection) after impact. The centrifugal stress, natural frequencies and resonance margins are computed after updating the blade geometry due to the local plastic deformations. The analyses are carried out employing a three node triangular plate element with six degrees of freedom per node. The dynamic response is computed via modal superposition technique. The effect of ice impact parameters such as speed and impact location on the optimization are discussed.

\section{BLADE DESIGN PROBLEM}

\section{Algorithm: Method of Feasible Directions}

The method of feasible directions ${ }^{3}$ solves the following inequality constrained optimization problem:

find the vector of design variables $\bar{X}$ which will 
subject to

$$
\begin{array}{ll}
g_{j}(\bar{X}) \leq 0 & j=1, \ldots m \\
X_{i}^{l} \leq X_{i} \leq X_{i}^{\mu} & i=1, \ldots n
\end{array}
$$

where $F$ is the objective function, $g_{j} s$ are the $m$ constraints and, $X_{i}^{l}$ and $X_{i}^{u}$ are the lower and upper bounds of the design variables.

The optimization process proceeds iteratively by the common update formula

$$
\bar{X}^{q}=\bar{X}^{q-1}+\alpha^{*} \bar{S}^{q}
$$

where $q$ is the iteration number, $\bar{S}^{q}$ the vector search direction, and $\alpha^{*}$ a scalar move parameter. Thus, optimization proceeds in two steps: first determine a "usable-feasible" search direction $\bar{S}^{q}$, and then perform a one-dimensional search in this direction to reduce the objective function as much as possible subject to the constraints. It is assumed here that the initial design $\bar{X}^{0}$ is feasible (satisfies all constraints), but if this is not so, a search direction that will direct the design back to the feasible region can be found.

The usable feasible search direction is found by solving the following subproblem ${ }^{3}$ :

$$
\text { Maximize } \beta
$$

subject to

$$
\begin{aligned}
& \vec{\nabla} F(\bar{X}) \cdot \bar{S}+\beta \leq 0 \\
& {[A] \bar{s}+\beta \bar{\theta} \leq 0} \\
& \bar{S} . \bar{S} \leq 1
\end{aligned}
$$

where $\bar{\theta}$ is the gradient operator and the rows of $[A]$ contain the transpose of the gradients of the set $J$ of currently active constraints, $\left[g_{j}(\bar{X})=0\right.$, within a specified tolerance for $\left.j \in J\right]$. The components of $\bar{\theta}$ are referred to as push-off factors, which push the design away from the currently active constraints (Figure 2). 
Having determined the search direction $\vec{S}$, Equation (4) is used to update the design vector as a function of $\alpha$ to reduce the objective function as much as possible, subject to the constraints.

\section{Example Blade and Model Description}

The SR2 unswept blade considered here is made of layered composite. The layup is symmetric with titanium skin and titanium core with graphite-epoxy plies in between ([Titanium/ GraphiteEpoxy/Titanium] $]_{s}$ ). The planform of the blade with finite element grid is shown in Figure 3. In constructing the thickness of the blade, it is assumed that the titanium skin is always present and the layup is symmetric. Depending upon the blade thickness at a given location, the graphite-epoxy plies are included to the specified limit. Also, the composite plies are alternately oriented starting with specified angle $\phi$ (see Figure 4). The remaining thickness is filled with titanium core.

The blade is modeled with 55 nodes and 80 triangular plate finite elements similar to the NASTRAN TRIA3 element. The element has six degrees of freedom at each node. To further increase the computational speed without sacrificing numerical accuracy, the total number of degrees of freedom have been reduced to 24 by employing the Guyan reduction scheme. ${ }^{4}$

The ice piece that impacts the blade is modeled as a spherical object. The ice impacts the leading edge of the blade with a high velocity. A schematic depicting the geometry of the ice piece impacting the blade is shown in Figure 5a. The angle $\theta$ at which ice impacts the blade is a function of the ice velocity and the engine speed (RPM). Depending on the diameter of the ice piece and the blade spacing, only a portion of the ice impacts the blade as shown in Figure 5b. Also, only the normal component of the impact force to the local chord is considered to cause the most damage locally and at the root 5

For the post-impacted blade, static root stresses due to centrifugal loading, natural frequencies and the corresponding resonance margin are computed by updating the geometry of the blade to include the plastic local impact deformations. ${ }^{6}$ 


\section{Objective Function}

The objective function considered for minimization is the weight of the blade. The expression for the weight of the blade is a summation over the number of elements and is given by

$$
F=\sum_{i=1}^{k} \rho_{i} v_{i} 8
$$

where $\rho_{i}$ is the density and $v_{\mathrm{i}}$ is the volume of $i^{\text {th }}$ element, and $g$ is the acceleration due to gravity. In the code the value of $F$ is obtained by using the lumped masses of the mass matrix.

\section{Design Variables}

The design variables considered for minimization of the weight are: root chord length (chord length at station 2), maximum thicknesses of the blade at five stations 2,5,7,9 and 11 (see Figure 3), and the graphite-epoxy ply orientation. The chord lengths of the blade at all (11) stations are scaled as root chord is changed during the optimization process. The thicknesses at other intermediate stations are interpolated with cubic splines based on the five design thicknesses (control points).

\section{Design Constraints}

For the minimum weight design of the blade, the constraints are placed on the behavior variables: average leading edge strain in the finite elements along the leading edge, root damage parameter due to ice impact, maximum stress at the root due to centrifugal loading, first three natural frequencies and resonance margin. A brief description of these constraints are given in the following subsections. The static root stress, natural frequencies and resonance margin constraints are calculated for the updated blade geometry due to local ice impact plastic deformations.

Leading Edge Strain Constraint: For computing the leading edge strain, the ice impact is considered as transient distributed load and only a specified region of the blade (Figure 6) is modeled for local impact analysis. 5,7 Since the damage caused by the impact is highly localized, only a portion of the blade around the impact region (i.e., a specified local patch along the span and half of the blade along the chord) is modeled. The patch is modeled using 35 nodes and 48 elements. A total of 16 elements surrounding the 
impact node are assumed to be fully stressed and undergo large deflection. The stiffnesses of these elements are modified to reflect perfectly plastic condition with an equivalent yield stress. Modal integration technique is employed to obtain the undamped transient response of the local impact region utilizing the first five modes of the blade. The average spanwise bending strain $(\varepsilon)$ in the elements along the leading edge is used as a local damage variable for the design constraint as

$$
\varepsilon \leq \varepsilon^{u}
$$

where $\varepsilon^{u}$ is the allowable upper bound. At the initial design, the variation of the strain with the ice speed is shown in Figure 7. The strain reaches a maximum value at an intermediate value of the ice speed due to the assumption that only the force component normal to the chord causes the local local damage.

Root Damage Constraint: In the case of root damage analysis ${ }^{8}$, the ice impact is modeled as an impulse load and the stress response at the root (second row of elements) is obtained by modal superposition technique using the first three modes. A combined ply stress failure function based on modified distortion energy ${ }^{9}$ is used as a measure of the root damage. A value of this function greater than unity is an indication of failure. If $\psi$ is the value of the failure function at any given state, the design constraint can be written as

$$
\psi \leq 1.0
$$

The predicted root damage function is larger for low values of ice speeds (Figure 7) ${ }^{8}$. At higher ice speeds, the damage goes to zero due to the inclusion of only the impulse normal to the chord in the analysis.

Maximum Static Reot Stress Constraint: After the ice impact, the radial stress caused by the centrifugal loading at the root of the blade (in the second row of elements, see Figure 3 ) is computed. It is assumed that maximum stress occurs at the top or bottom of the blade in the titanium material. An upper bound constraint is placed on the maximum root stress $\left(\sigma_{\max }\right)$ as follows:

$$
\sigma_{\max } \leq \sigma^{u}
$$

Natural Frequency Constraints: The determination of natural frequencies for rotating blades requires the inclusion of differential stiffness effects due to centrifugally induced stresses. In order to allow for 
differential stiffness generation, static deflections are determined for the case of centrifugal loading and then these are used to create differential stiffness matrix. The lower bound constraints on the first three natural frequencies of post ice impacted blade are:

$$
f_{i} \geq f_{i}^{l}, i=1,2,3
$$

where $f_{i}^{l}$ is the lower bound value for $i^{\text {th }}$ mode frequency.

Resonance Margin Constraint: For any rotational system, forced response may be generated due to multiple sources of excitation. The rotor speeds at which forced responses occur are predicted based on the "Campbell" or speed-frequency diagrams. These display the natural frequency of each blade mode versus rotor speed and, at the same time, the forcing function frequency (or engine order $E$ lines) versus rotor speed, as indicated schematically in Figure 8 . These $E$ lines represent the loci of available excitation energy at any rotational speed for $1,2,3$, etc. excitations per revolution. Wherever these curves intersect, a potential source of destructive forced response exists. Not all intersections can be avoided. Design practice is to eliminate the lower-order excitations from the operating range whenever possible. This is because the sources of most forced response energy usually result from these lower-order resonances, particularly the $2 E$ lines. 9

The variation of natural frequency with speed may be nearly approximated as:

$$
f^{2}=f_{0}^{2}+B N^{2}
$$

where $f_{0}$ is the zero speed frequency, and $N$ is the engine RPM. To evaluate the modal speed sensitivity, B, frequencies at two discrete speeds must be determined. If both speeds are selected from the engine running speed range (minimum cruise speed, $N_{m c}$ - Redline speed, $N_{r}$ ), the frequency estimate will be quite close over the entire running range. In the BLASIM code, the above two constants $\left(f_{0}\right.$ and $\left.B\right)$ are computed using the frequency values at operating speed $\left(N_{o p}\right)$ and at an RPM close to redline speed $\left(N_{2}=0.9 N_{r l}\right)$. Then the frequencies at minimum cruise speed $\left(f_{m c}\right)$ and at redline speed $\left(f_{r l}\right)$ are given by

$$
f_{m c}^{2}=f_{0}^{2}+B\left(N_{m c}^{2}-N_{o p}^{2}\right)
$$




$$
f_{n}^{2}=f_{0}^{2}+B\left(N_{r}^{2}-N_{o p}^{2}\right)
$$

From these frequencies, the resonance margin as a fraction of excitation frequency for a given mode and order is given by

$$
M=\max \left\{\frac{\left(r N_{m c}-60 f_{m c}\right)}{r N_{m c}}, \frac{\left(60 f_{r l}-r N_{r l}\right)}{r N_{r l}}\right\}
$$

Due to the nature of the response curve (flat compared to the engine order $E$ lines) only one of the terms, (i.e., either margin at minimum cruise speed or at the redline speed) in the parenthesis is positive. The resonance margin constraint for post ice impacted blade can be written as

$$
M \geq M^{l}
$$

where $M^{l}$ is the lower limit of the margin.

\section{RESULTS AND DISCUSSION}

For the numerical study of the structural tailoring problem, the setting angle of the SR2 blade is chosen as $57^{\circ}$ and the number of blades is eight. The maximum graphite-epoxy material layer thickness is $0.02^{\prime \prime}$ ( 4 plies on either side of the symmetric plane). The properties of the titanium and graphite-epoxy composite ply are given in Table 1. For the local damage analysis, the equivalent yield stress around the impact region is assumed to be $206 \mathrm{ksi}$.

\section{Effect of Ice Speed}

The tailoring studies are performed for a number of ice speeds in the range 25-250 knots. The ice impact region is assumed to be $50-90 \%$ span of the blade. The summary of the optimization results along with the initial design vector and constraint values are given in Table 2. A typical iteration history of the optimization run is shown in Figure 9. This is for an ice speed of 125 knots at which initial design violated the leading edge strain constraint. Hence the optimization method initially tries to minimize the constraint violation and as a result, there is an increase of the objective function for the first few iterations. 
Once the design point is moved inside the feasible region, the objective function decreases in the subsequent iterations.

For a few ice speeds, namely, 50, 100, 150 and 250 knots, initial and constrained optimum blades thickness profiles are shown in Figure 10. It can be seen that thickness at station 2 has strong influence on the blade weight as well as the behavior variables, especially leading edge strain and root damage function. For 50 and 100 knots, the root damage constraint is violated by wide margin initially and hence there is an increase in the thickness at station 2. However, the objective function is decreased at the optimum marginally (5.9\%) due to reduction in other thickness variables and root chord. At the ice speeds 150 and 250 knots, the optimum blade thicknesses are smaller. This is due to the fact that impact responses are lower (see Figure 7) and only the natural frequency constraints controlled the design.

At the initial design, the root damage function is maximum near 25 knots and the strain is maximum near 100 knots (Figure 7). Accordingly, the constraints on these variables have maximum violation at the corresponding ice speeds (see Table 2). As a result, the minimum weight design resulted in an increase in the blade weight by $2 \%$ at 25 knots and $9.4 \%$ at 100 knots. The final design at 25 knots could not satisfy the root damage constraint as it hit the first and third natural frequency constraint boundary. For higher ice speeds, the optimum designs are mostly controlled by the bounds on natural frequencies. The root stress and resonance margin constraints are satisfied and are not active for the entire range of ice speeds considered. Also, the graphite-epoxy ply angle has negligible effect on the optimization. It remained more or less constant at $45^{\circ}$ except for ice speed of 250 knots. Only one resonance margin (intersection of mode $1,-2^{\text {nd }}$ excitation order) constraint is imposed and it is not active in all the designs

\section{Effect of Ice Impact Region}

To study the effect of ice impact region, three patches, namely, $25-65 \%, 40-80 \%$ and $50-90 \%$ span of the blade are chosen. As the impact region is changed, the radius at which the ice impacts the blade changes. The ice impact location is approximately $(\approx 45 \%, \approx 60 \%$ and $\approx 70 \%)$ at midpoint of the region. The optimum designs for an ice speed of 150 knots are compared in Table 3. As the impact is closer to the root, 
the leading edge strain and the root damage function are smaller and hence are not critical for the final design state as expected. The optimum designs in all the cases are controlled by the natural frequency constraints. Though the root damage function constraint is violated for $40-80 \%$ and $50-90 \%$ regions, it is inactive at the optimum.

\section{CONCLUSIONS}

From the tailoring studies performed on the SR2 composite blade subject to ice impact constraints, the following conclusions can be drawn:

1. The blade thickness at station 2 and the root chord have significant effect on the blade weight as well as the leading edge strain and root damage function.

2. The minimum weight designs appears to be insensitive to the changes in graphite-epoxy ply angle.

3. For higher ice speeds, the optimum results are controlled by natural frequency constraints.

4. When ice impacts closer to the root of the blade the optimum design is governed by natural frequency constraints.

\section{REFERENCES}

1. Reddy, E. S.; Abumeri, G. H.: Blade Assessment for Ice Impact (BLASIM), User's Manual. NASA CR to be published.

2. Reddy, T. S. R.; Kaza, K. R. V.: Analysis of an Unswept Propfan Blade With a Semiempirical Dynamic Stall Model. NASA TM 4083, 1989.

3. Vanderplaats, G. N.: An Efficient Feasible Directions Algorithm for Design Synthesis. AIAA Journal, Vol. 22, November 1984.

4. Guyan, R. J.: Reduction of Stiffness and Mass Matrices. AIAA Journal, Vol. 3.2, Februray 1965. 
5. Brown, K. W: Structural Tailoring of Engine Blades (STAEBL), Theoretical Manual. NASA CR $175112,1986$.

6. Abumeri, G. H. ; Reddy, E. S.; Murthy, P. L. N.; and Chamis, C. C.: Dynamic Analysis of Pre-andPost Ice Impacted Blade. AIAA Aircraft Design Systems Meeting, August 24-26, Hilton Head, S.C., 1992.

7. Reddy, E. S.; Abumeri, G. H.; Chamis C. C.; and Murthy, P. L. N.: Analysis of Aircraft Engine Blade Subject to Ice Impact. NASA TM 105336, 1991.

8. Reddy, E. S.; Abumeri, G. H.; Chamis C. C.; and Murthy, P. L. N.: Root Damage Analysis of Aircraft Engine Blade Subject to Ice Impact. NASA TM 105779, 1992.

9. Murthy, P. L. N.; and Chamis C. C.: Integrated Composite Analyzer (ICAN), Users and Programmers Manual. NASA TP 2515, 1986.

10. Avallone, E. A.; and Baumeister III, T.: Mark's Standard Handbook for Mechanical Engineers. Ninth Edition, McGraw-Hill Book Company, N.Y.,1987. 

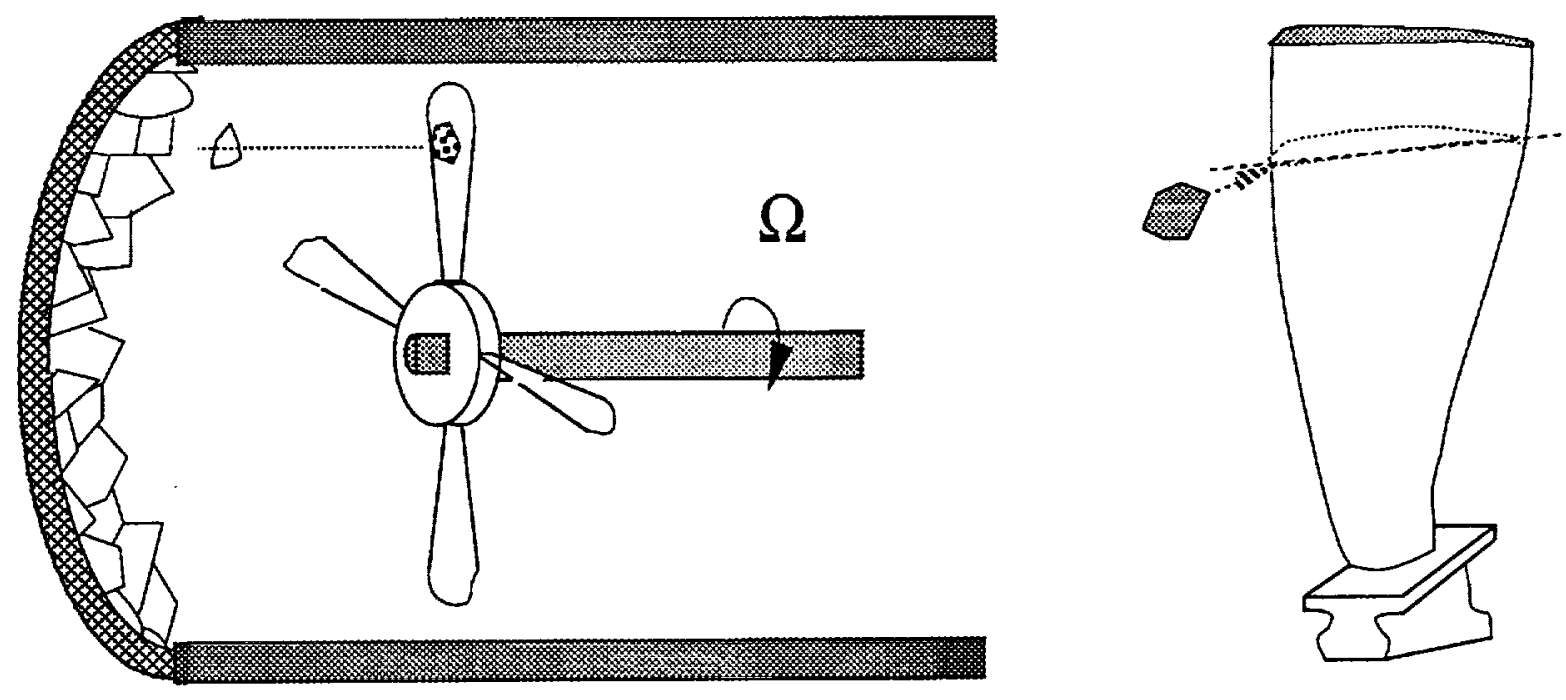

Figure 1. A Schematic of Ice Impact on an Engine Blade

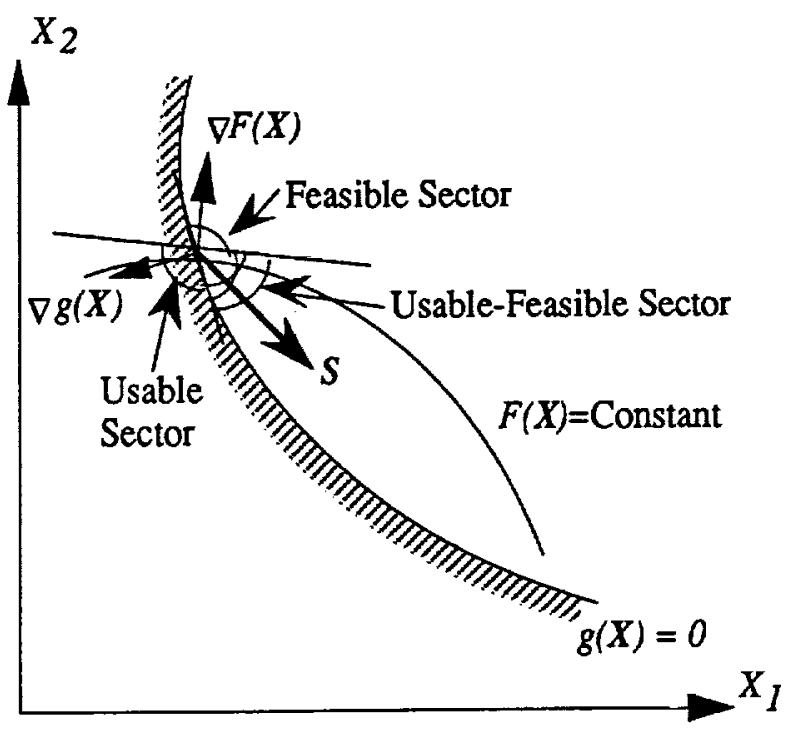

Figure 2. Geometric Interpretation of Feasible Direction in the Optimization 


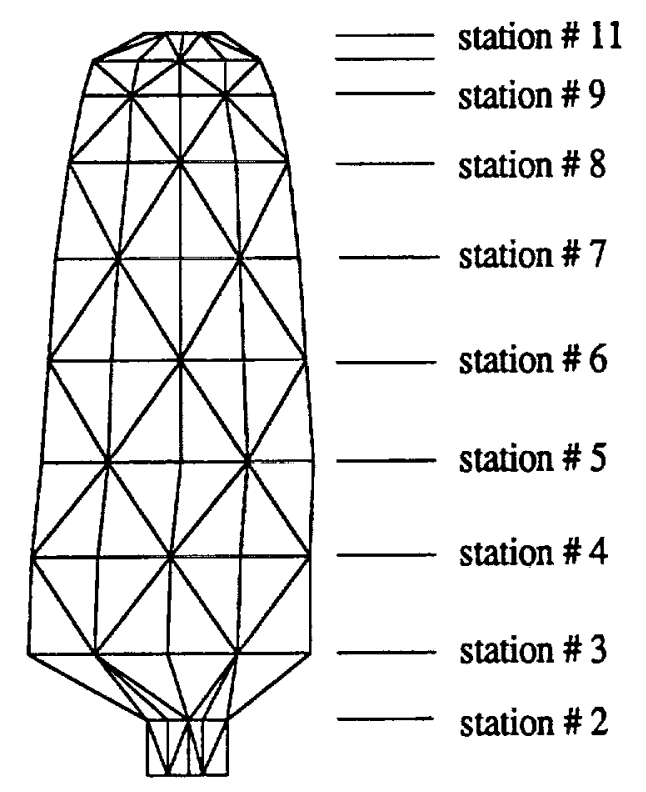

Figure 3. Planform of the Blade and Finite Element Grid

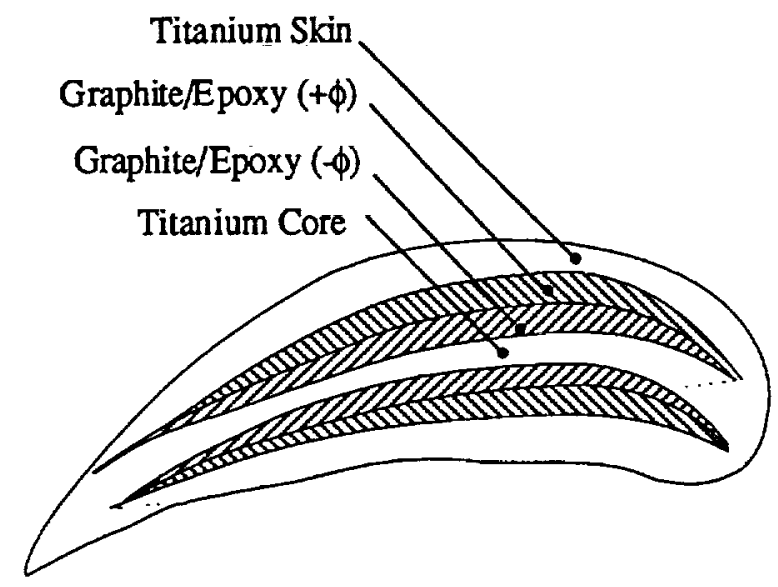

Figure 4. Blade Cross Section and Ply Layup 


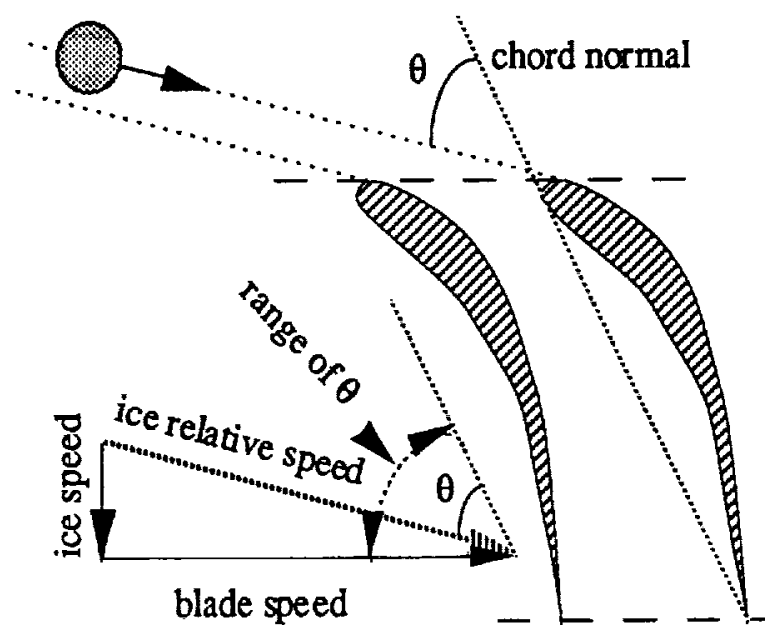

(a)

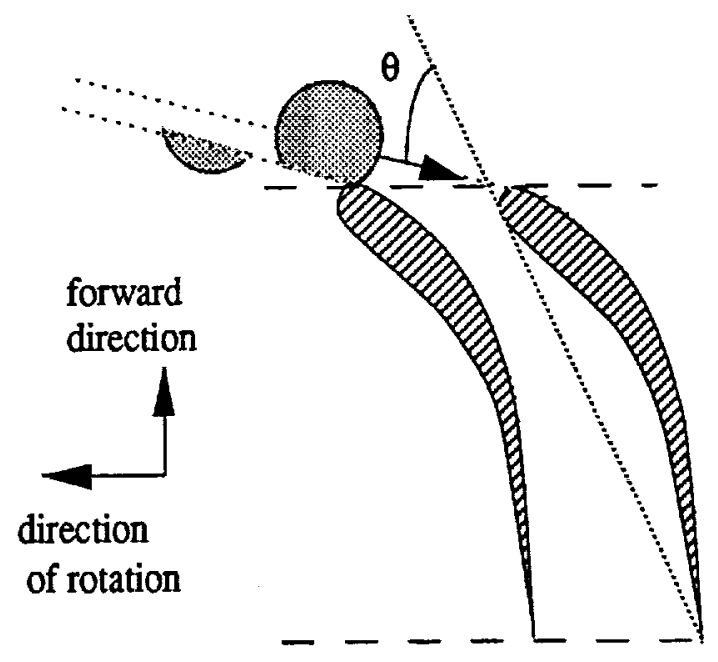

(b)

Figure 5. Geometry of Ice Impact on an Engine Blade 


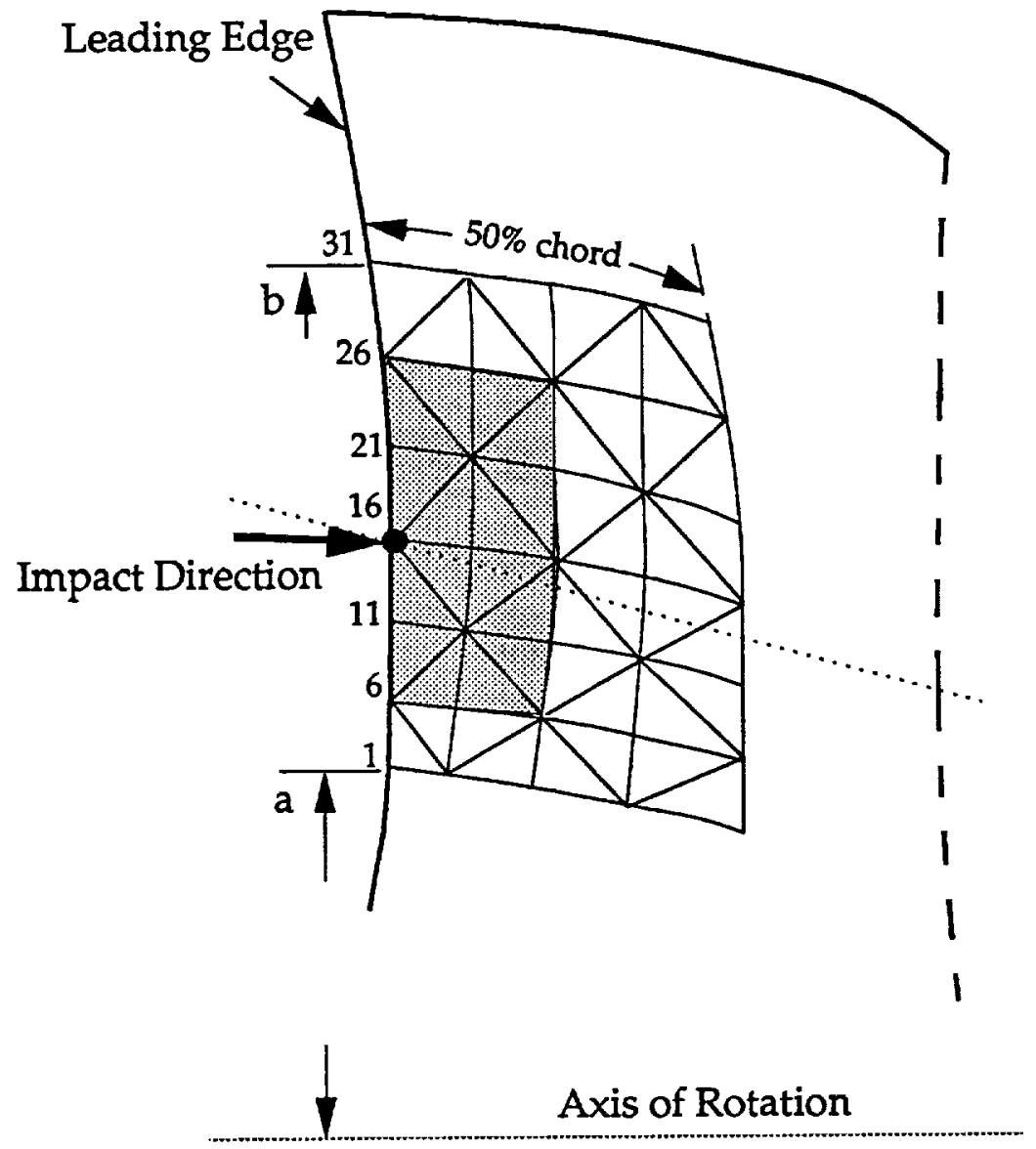

Special Elements with yielding

- Local Impact Node

Figure 6. Finite Element Model for Local Impact Analysis 


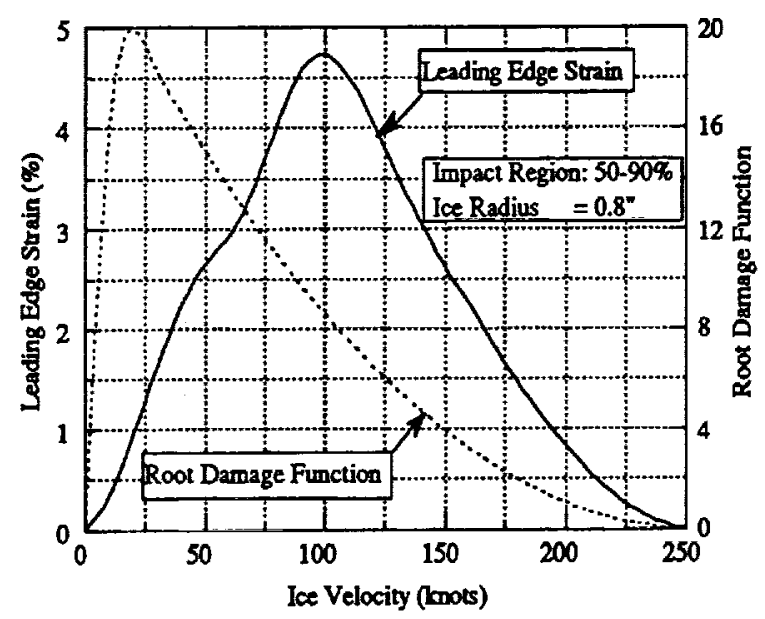

Figure 7. Variation of Leading Edge Strain and Root Damage Function as a Function of Ice Speed at the Initial Design

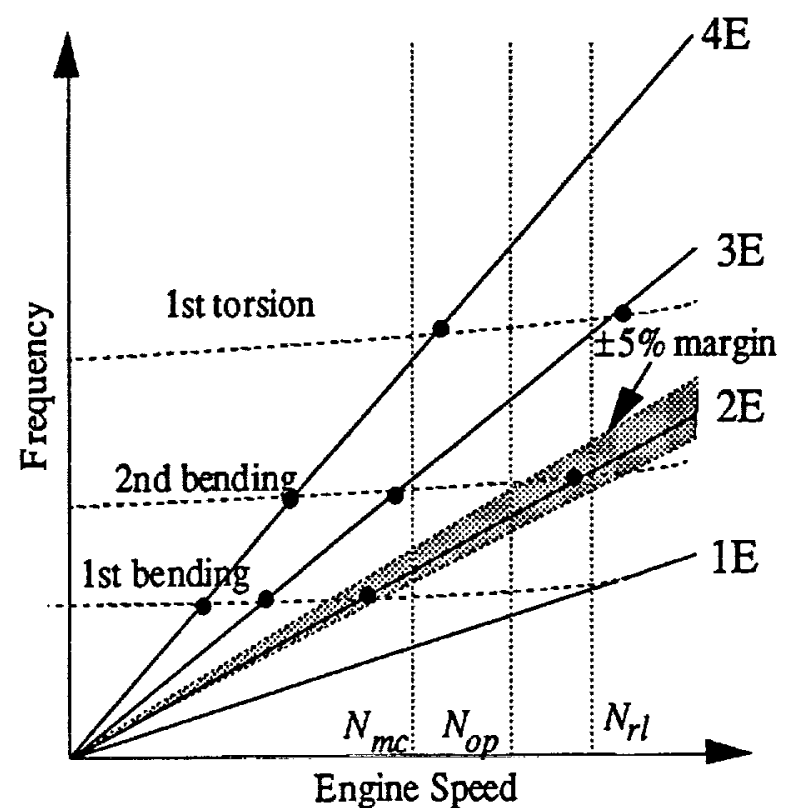

Figure 8. Speed-Frequency and Resonance Margin Diagram 


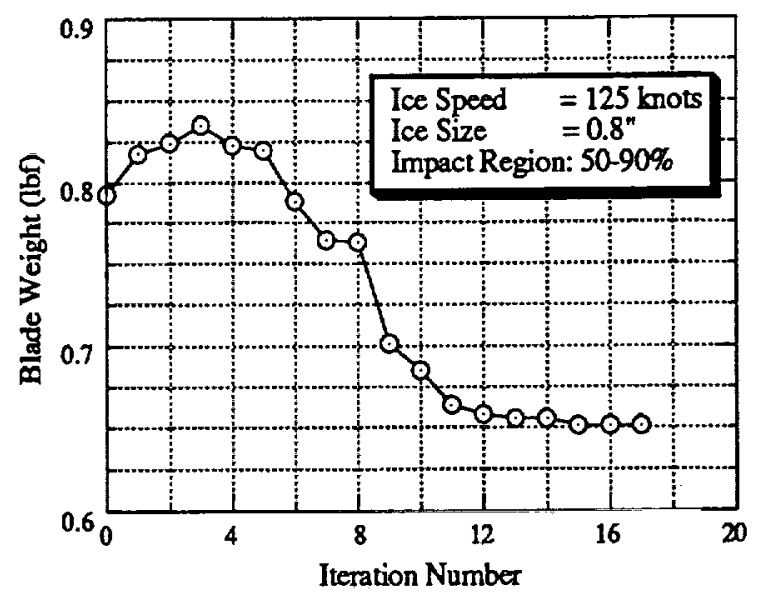

Figure 9. Iteration History of Optimization - Variation of Objective Function

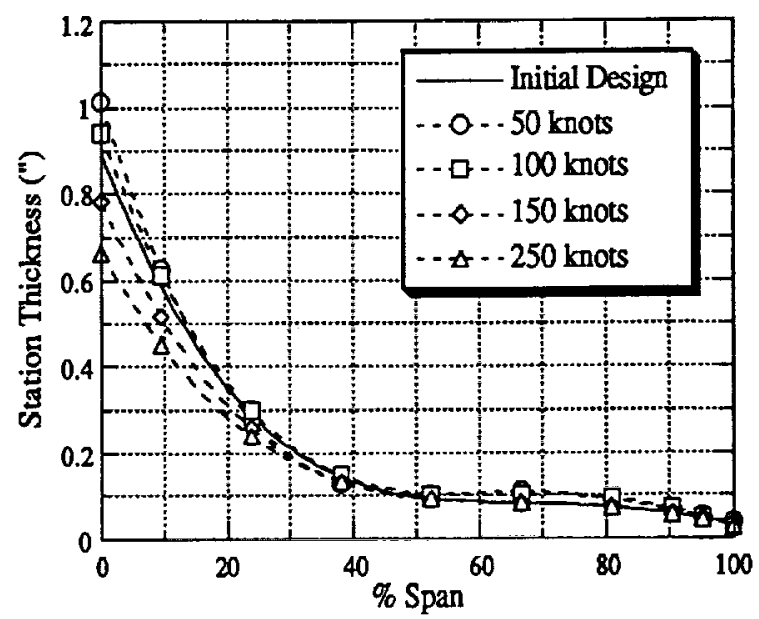

Figure 10. Initial and Optimum Thickness Profile of Ice Impacted Blade 
Table 1: Properties of the Blade Constituent Materials

\begin{tabular}{|c|c|c|c|c|c|c|}
\hline $\begin{array}{c}\text { Material } \\
\text { Type }\end{array}$ & $\begin{array}{c}E_{I 1} \\
\left(10^{6} \mathrm{psi}\right)\end{array}$ & $\begin{array}{c}E_{22} \\
\left(100_{\mathrm{psi}}\right)\end{array}$ & $\begin{array}{c}G_{I 2} \\
\left(10^{6} \mathrm{psi}\right)\end{array}$ & $v_{l 2}$ & $\begin{array}{c}\rho \\
\left(1 \mathrm{bsec} 2 / \mathrm{in}^{4}\right)\end{array}$ & $\begin{array}{c}\text { ply } \\
\text { thickness (") }\end{array}$ \\
\hdashline $\begin{array}{c}\text { Titanium } \\
\text { (Ti6) }\end{array}$ & 16.5 & 16.5 & 6.4 & 0.30 & $4.4 \times 10^{-4}$ & - \\
\hdashline $\begin{array}{l}\text { Graphite } \\
\text { Epoxy }\end{array}$ & 32.0 & 1.0 & 0.7 & 0.25 & $1.5 \times 10^{-4}$ & 0.005 \\
\hline
\end{tabular}




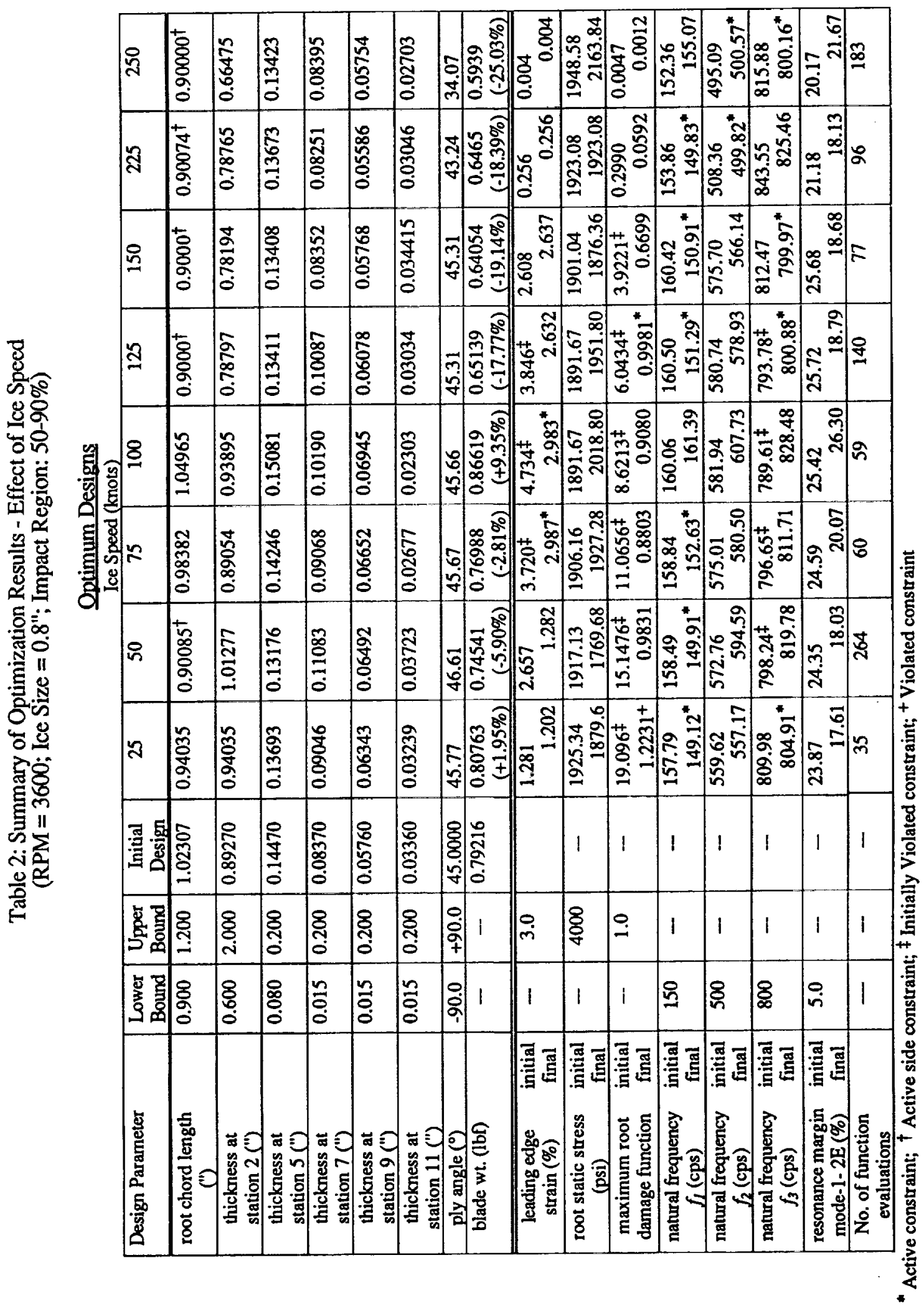


Table 3: Summary of Optimization Results - Effect of Impact Region $(\mathrm{RPM}=3600$; Ice Size $=0.8 "$; Ice Speed $=150$ knots $)$

Optimum Designs

Ice Impact Region (\% Span)

\begin{tabular}{|c|c|c|c|c|c|c|}
\hline $\begin{array}{c}\text { Design } \\
\text { Parameter }\end{array}$ & $\begin{array}{l}\text { Lower } \\
\text { Bound }\end{array}$ & $\begin{array}{l}\text { Upper } \\
\text { Bound }\end{array}$ & $\begin{array}{l}\text { Initial } \\
\text { Design }\end{array}$ & $25-65 \%$ & $40-80 \%$ & $50-90 \%$ \\
\hline $\begin{array}{l}\text { root chord length } \\
(1)\end{array}$ & 0.900 & 1.200 & 1.02307 & $0.9000^{\dagger}$ & $0.90000^{\dagger}$ & $0.9000^{\dagger}$ \\
\hline $\begin{array}{l}\text { thickness at } \\
\text { station } 2(")\end{array}$ & 0.600 & 2.000 & 0.89270 & 0.84094 & 0.66181 & 0.78194 \\
\hline $\begin{array}{l}\text { thickness at } \\
\text { station } 5 \text { (") }\end{array}$ & 0.080 & 0.200 & 0.14470 & 0.15942 & 0.14984 & 0.13408 \\
\hline $\begin{array}{l}\text { thickness at } \\
\text { station } 7 \text { (") }\end{array}$ & 0.015 & 0.200 & 0.08370 & 0.09126 & 0.11470 & 0.08352 \\
\hline $\begin{array}{l}\text { thickness at } \\
\text { station } 9 \text { (") }\end{array}$ & 0.015 & 0.200 & 0.05760 & 0.04266 & 0.04997 & 0.05768 \\
\hline $\begin{array}{l}\text { thickness at } \\
\text { station } 11(")\end{array}$ & 0.015 & 0.200 & 0.03360 & 0.02555 & 0.02974 & 0.034415 \\
\hline ply angle $\left(^{\circ}\right)$ & -90.0 & +90.0 & 45.0000 & 42.58 & 45.2807 & 45.31 \\
\hline blade wt. (lbf) & - & - & 0.79216 & $\begin{array}{c}0.70252 \\
(-11.31 \%)\end{array}$ & $\begin{array}{c}0.62524 \\
(-21.07 \%)\end{array}$ & $\begin{array}{c}0.64054 \\
(-19.14 \%)\end{array}$ \\
\hline $\begin{array}{cc}\text { leading edge } & \text { initial } \\
\text { strain (\%) } & \text { final } \\
\end{array}$ & $\overline{---}$ & $\overline{3.0}$ & - & $\begin{array}{l}0.1077 \\
0.066 \\
\end{array}$ & $\begin{array}{l}0.7110 \\
0.411 \\
\end{array}$ & $\begin{array}{l}2.608 \\
2.637 \\
\end{array}$ \\
\hline $\begin{array}{cc}\begin{array}{c}\text { root static stress } \\
\text { (psi) }\end{array} & \begin{array}{c}\text { initial } \\
\text { final }\end{array} \\
\end{array}$ & --- & 4000 & $-\infty$ & $\begin{array}{l}1936.78 \\
1987.44 \\
\end{array}$ & $\begin{array}{l}1931.04 \\
2381.96 \\
\end{array}$ & $\begin{array}{l}1901.04 \\
1876.36 \\
\end{array}$ \\
\hline $\begin{array}{cc}\text { maximum root } & \text { initial } \\
\text { damage function } & \text { final } \\
\end{array}$ & $\overline{-\infty}$ & 1.0 & - & $\begin{array}{l}0.6522 \\
0.0061 \\
\end{array}$ & $\begin{array}{l}3.5231^{\ddagger} \\
0.4169 \\
\end{array}$ & $\begin{array}{l}3.9221^{\ddagger} \\
0.6699\end{array}$ \\
\hline $\begin{array}{cc}\begin{array}{c}\text { natural frequency } \\
f_{l} \text { (cps) }\end{array} & \text { initial } \\
\end{array}$ & 150 & - & $-\cdots$ & $\begin{array}{l}160.11 \\
181.29 \\
\end{array}$ & $\begin{array}{l}170.94 \\
169.19 \\
\end{array}$ & $\begin{array}{c}160.42 \\
150.91^{*} \\
\end{array}$ \\
\hline $\begin{array}{cc}\text { natural frequency } & \text { initial } \\
f_{2}(\mathrm{cps}) & \text { final } \\
\end{array}$ & 500 & - & - & $\begin{array}{l}494.13^{\ddagger} \\
500.28^{*} \\
\end{array}$ & $\begin{array}{l}528.22 \\
514.53 \\
\end{array}$ & $\begin{array}{l}575.70 \\
566.14 \\
\end{array}$ \\
\hline $\begin{array}{cc}\begin{array}{c}\text { natural frequency } \\
f_{3} \text { (cps) }\end{array} & \begin{array}{c}\text { initial } \\
\text { final }\end{array} \\
\end{array}$ & 800 & -- & - & $\begin{array}{l}742.34 \ddagger \\
838.98 \\
\end{array}$ & $\begin{array}{l}686.67^{\ddagger} \\
797.42^{*} \\
\end{array}$ & $\begin{array}{l}812.47 \\
799.97^{*}\end{array}$ \\
\hline $\begin{array}{|cc|}\text { resonance } & \text { initial } \\
\text { margin mode-1- } & \text { final } \\
2 \mathrm{E}(\%) & \\
\end{array}$ & 5.0 & - & $\cdots$ & $\begin{array}{l}25.66 \\
40.92\end{array}$ & $\begin{array}{l}33.10 \\
31.29\end{array}$ & $\begin{array}{l}25.68 \\
18.68\end{array}$ \\
\hline $\begin{array}{c}\text { No. of function } \\
\text { evaluations }\end{array}$ & $\overline{---}$ & $\cdots$ & - & 105 & 78 & 77 \\
\hline
\end{tabular}

* Active constraint; $†$ Active side constraint; $¥$ Initially Violated constraint; + Violated constraint 


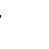




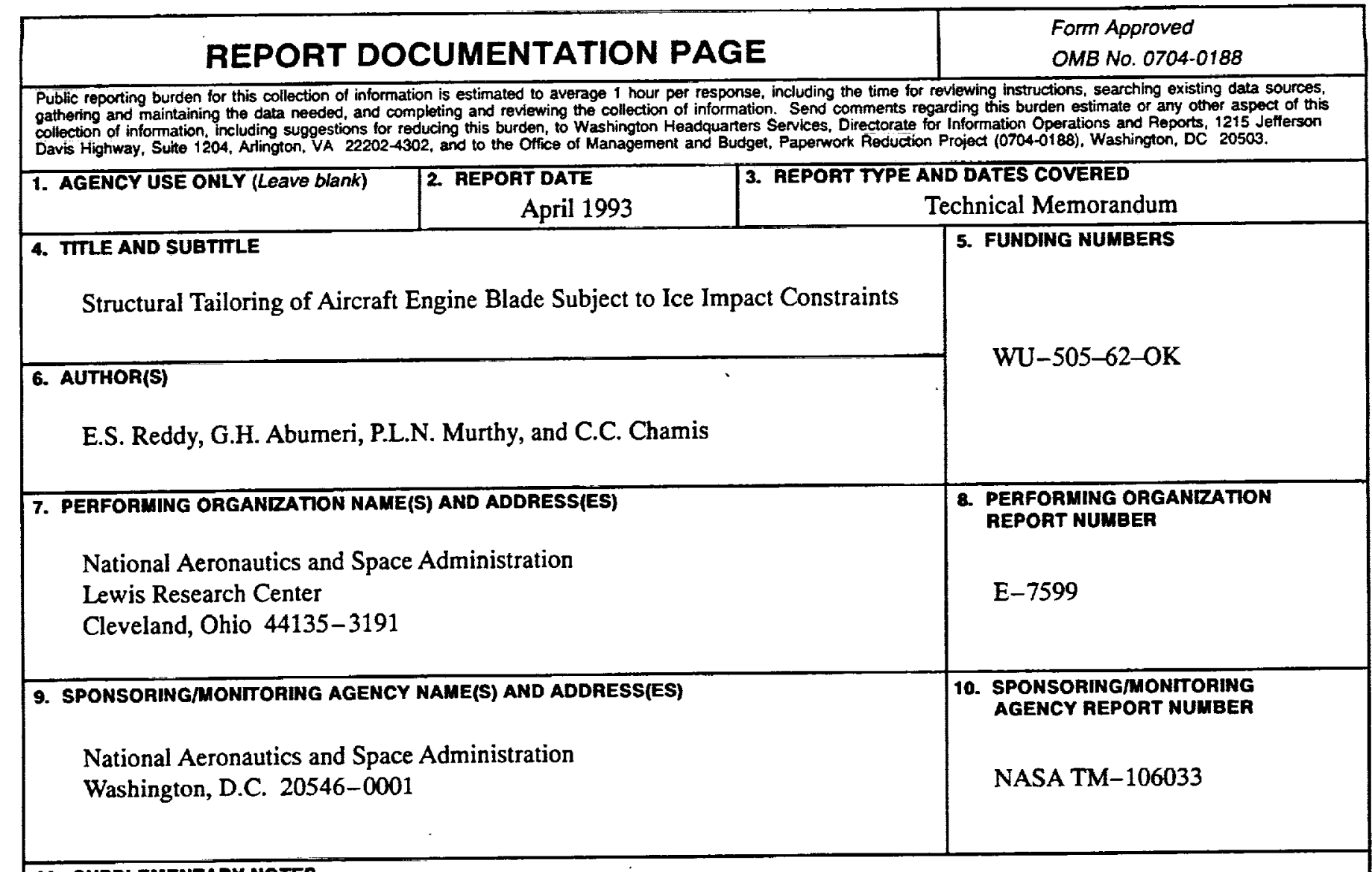

\section{SUPPLEMENTARY NOTES}

Prepared for the Fourth AIAA/Air Force/NASA/OAI Symposium on Multidisciplinary Analysis cosponsored by the AIAA, USAF, NASA, and OAI, Cleveland, Ohio, September 21-23, 1992. E.S. Reddy and G.H. Abumeri, Sverdrup Technology, Inc., Lewis Research Center Group, 2001 Aerospace Parkway, Brook Park, Ohio 44142. P.L.N. Murthy and C.C. Chamis, NASA Lewis Research Center. Responsible person, C.C. Chamis, (216) 433-3252.

12a. DISTAIBUTION/AVAILABILTYY STATEMENT

12b. DISTRIBUTION CODE

Unclassified -Unlimited

Subject Category 39

13. ABSTRACT (Max/mum 200 words)

Results are presented for the minimum weight design of SR2 unswept blade made of [Titanium/Graphite-Epoxy/

Titanium $]_{S}$ fiber composite. The blade which is rotating at high RPM is subject to ice impact. The root chord length, blade thicknesses at five stations, and graphite-epoxy ply orientation are chosen as design variables. Design constraints are placed on the behavior variables: local leading edge strain and root damage parameter (combined stress failure criteria) as a function due to ice impact, maximum spanwise centrifugal stress at the root of the deformed blade due to local damage, first three natural frequencies and resonance margin after impact. The method of feasible directions is employed to solve the inequality constrained minimization problem. The effect of ice speed and the ice impact location on the final design are discussed.

\section{SUBJECT TERMS}

Fan blades; Fiber composites, Impact damage; Impact loads; Transient response; Finite element method; Behavior constraint; Design optimization

\begin{tabular}{|c|c|c|}
\hline $\begin{array}{c}\text { 17. SECURITY CLASSIFICATION } \\
\text { OF REPORT } \\
\text { Unclassified }\end{array}$ & $\begin{array}{c}\text { 18. SECURITY CLASSIFICATION } \\
\text { OF THIS PAGE } \\
\text { Unclassified }\end{array}$ & $\begin{array}{c}\text { 19. SECUATY CLASSIFICATION } \\
\text { OF ABSTRACT } \\
\text { Unclassified }\end{array}$ \\
\hline
\end{tabular}

15. NUMBER OF PAGES

22

16. PRICE CODE

$\mathrm{A03}$

20. LIMITATION OF ABSTRACT

Standard Form 298 (Rev. 2-89)

Prescribed by ANSI Std. Z39-18 298-102 